\title{
Neediness and depression in women
}

\author{
Rui C. Campos, PhD \\ Isabel Mesquita, $\mathrm{PhD}$ \\ Avi Besser, PhD \\ Sidney J. Blatt, $\mathrm{PhD}$
}

In a 6-month longitudinal design, the authors examined the links between neediness and increases in depressive symptoms in women. Neediness was assessed with the self-report Depressive Experiences Questionnaire (DEQ), supplemented by a projective measure that assessed an important component of dependency, oral dependency, on the Rorschach. Results indicate that neediness correlated significantly with increases in depressive symptoms over the 6 months. Orality interacted with neediness to substantially increase the prediction of increases in depressive symptoms. (Bulletin of the Menninger Clinic, 78[1], 16-33)

Freud in Mourning and Melancholia (1917/1980) attempted to integrate two different personality dimensions, orality and a punitive harsh superego, in a unified conceptualization of the etiology and nature of depression (melancholia). Blatt (1974), however, proposed that these two personality dimensions in depression, originally articulated by Freud, should be viewed as two independent sources or types of depression: an oral dependent ("anaclitic") and a self-critical, superego ("introjective") type of depression. Extensive theory, research, and clinical evidence (see reviews in Blatt, 2004, 2008) support this distinction. But much of this evidence has primarily elucidated self-critical depression,

\footnotetext{
This article was accepted under the editorship of Dr. W. Walter Menninger.

Rui C. Campos and Isabel Mesquita are in the Department of Psychology at the University of Évora, Portugal. Dr. Campos is also with the Research Center for Education and Psychology (CIEP) at the university. Avi Besser is in the Department of Behavioral Sciences and the Center for Research in Personality, Life Transitions, and Stressful Life Events at Sapir Academic College, D. N. Hof Ashkelon, Israel. Sidney J. Blatt is professor emeritus at Yale University, New Haven, Connecticut.

Grateful thanks are extended to the participants in this study.

Correspondence may be sent to Rui C. Campos, Department of Psychology, University of Évora, Apartado 94, Évora, Portugal 7002-554; e-mail: rcampos@uevora.pt (Copyright (C) 2014 The Menninger Foundation)
} 